\title{
Pulse Dye Laser Therapy for Spider Naevi
}

Dr Jamish Gandhi ${ }^{1}$ Dr Ali Aldawood ${ }^{1}$ Professor Swee T Tan1,2,3

\section{Abstract}

Aims: The aim of this study was to determine the treatment outcome of spider naevi using pulse dye laser (PDL) therapy.

Patients and Methods: This was a retrospective study reviewing the results of PDL on spider naevi in 49 consecutive patients undergoing PDL for spider naevi, between 15 October 2003 and 19 August 2008. A questionnaire was used to investigate patient satisfaction and recurrence.

Results: There was improvement seen in all patients with complete resolution in 31 patients (76\%) and 67 lesions (82\%).

There was a high level of satisfaction with the treatment with 30 patients (78\%) being very satisfied and six (15\%) satisfied with the result. Hypopigmentation occurred in one patient. Two patients (4.9\%) with a total of four lesions developed recurrence in two lesions only.

Conclusions: PDL is an effective and safe treatment of spider naevi.
1 Laser Service, Wellington Regional Plastic, Maxillofacial \& Burns Unit, Hutt Hospital.

2 University of Otago.

3 Gillies McIndoe Research Institute, Wellington, New Zealand.

\section{Contact information:}

Jamish Gandhi

” j.gandhi@xtra.co.nz

\section{Keywords}

Spider naevi, Pulse dye laser, Vascular lesion

\section{Introduction}

Spider naevi are benign cutaneous vascular lesions that involve a group of pulsatile and dilated arterioles. The collection of these vessels has a centre that blanches when pressure is applied to its centre. ${ }^{1}$ These lesions are common and occur in 15 percent of children and adults. ${ }^{2}$ Although they are harmless, they may cause significant cosmetic problems. They commonly appear on exposed areas such as the face, upper trunk and upper limbs ${ }^{2-5}$ and less commonly on the lower limbs and lower trunk. ${ }^{4}$

Various treatment modalities such as electrocautery, sclerotherapy and laser therapy have been used for spider naevi. Electrocautery may be associated with excessive bleeding and scarring. Older lasers, including the argon laser, have been associated with an unacceptably high incidence of scarring and pigmentary changes. ${ }^{2}$

Previous reports 2,5 show effectiveness of PDL on spider naevi however, follow up has been limi- 
ted. The aim of this study was to determine the treatment outcome of spider naevi using pulse PDL.

\section{Patients and Methods}

This was a retrospective study which reviewed consecutive patients undergoing PDL for spider naevi at our laser service between 15 October 2003 and 19 August 2008.

The patients were culled from our prospective laser database and information was supplemented by review of the medical records. The information collected was of the age, sex, number and location of the lesions, the number of treatment sessions for each patient.

PDL treatment was carried out as an outpatient procedure using the Candela $V$ Beam with a dynamic cooling device (set at 30/30) using fluences of 10.5 joules/cm2 and $1.5 \mathrm{msec}$ using a $7 \mathrm{~mm}$ hand piece. An additional pulse of 15 joules/cm2 at $6 \mathrm{msec}$ using $5 \mathrm{~mm}$ hand piece to lesions with a raised centre. The number of pulses depended on the size of lesions overlapped by $1 \mathrm{~mm}$.

A questionnaire was dispatched to adult patients and the parents of children on previous treatments, outcomes, recurrence, side effects and satisfaction. Those who had not responded within four weeks were telephoned and the questionnaire was completed.

Data were entered into a Microsoft Excel spreadsheet and analysed.

\section{Results}

49 patients aged 7 months to 63 years (mean, 21 years) with 76 (mean, 1.6; range 1-5) spider naevi were treated with PDL. 39 (80\%) patients were females. The lesions were located on the face $(n=65)$ and upper limbs $(n=11)$. Eight $(20 \%)$ patients had previous unsuccessful treatment to $\mathrm{PDL}$ with liquid nitrogen $(n=2)$ and, electrocautery $(n=5)$ and topical cream $(n=1)$.

41 (84\%) patients completed and returned the questionnaire. The average follow-up period was 46 (range, 15-66) months. 28 patients were contacted by phone and completed the questionnaires. Eight patients were not contactable.

Complete resolution of the lesions occurred in 31 patients (76\%) with 67 lesions (82\%). Out of these, 25 patients (81\%) with 45 lesions (67\%) resolved completely after only one treatment. Three patients with seven lesions (10\%) required two treatments. One with one lesion (1.5\%) underwent three treatments. One with one lesion (1.5\%) had four and one with one lesion (1.5\%) had eight.

10 patients (24\%) had partial resolution. Two patients moved cities during treatment and had not completed their treatment course.

Six out of the eight patients who had previous treatment had complete resolution whilst the two who had electrocautery before had partial resolution.

Two patients (4.9\%) with a total of four lesions developed recurrence in two lesions only.

Five patients developed temporary hyperpigmentation and one patient experienced hypopigmentation.

30 of the 41 responders (73\%) were very satisfied and six (15\%) were satisfied with the result. One patient of the 41 responders (2.4\%) who was very dissatisfied did not complete the treatment as she had relocated cities following two treatments. She recommended the treatment for others and stated she would like to come back for further treatment. Another patient who developed a partial recurrence one year following treatment was dissatisfied with the outcome.

38 patients out of 41 (93\%) would recommend the treatment to others. Two patients (4.9\%) said they did not know and one (2.4\%) said no. 


\section{Discussion}

This study shows an overall satisfactory response to PDL with complete eradication of spider naevi in $76 \%$ of cases with 55 lesions (82\%) with a recurrence in $6.5 \%$ of patients and $3.6 \%$ of lesions with an average of 3.5 years follow up. Most patients would recommend PDL to others. Side effects were usually mild and temporary and this reflected the selectivity of PDL in targeting vascular structures and preventing damage to surrounding structures. ${ }^{2}$

\section{Conclusion}

To our knowledge this is the largest study on spider naevi treated with PDL in terms of number of patients and also the longest follow-up period.

PDL is effective and safe for the treatment of spider naevi.

\section{References}

1. Cotran RS, Kumar V, Collins T. Robbins Pathologic Basis of Disease, 6th edn, WB Saunders Company, USA.

2. Tan E, Vinciullo C. Pulsed dye laser treatment of spider telangiectasia. Australas J Dermatol. 1997;38(1):22-5.

3. Douglass W, Montgomery MD. Treatment of spider nevus. Arch Derm Syphilol. 1933;27(6):971-2.

4. Pack GT, Miller TR. Hemangiomas: Classification, diagnosis and treatment. Angiology 1950;1:405-26.

5. Polla LL, Tan OT, Garden JM, Parrish JA. Tunable pulsed dye laser for the treatment of benign cutaneous vascular ectasia. Dermatologica. 1987;174:11.
Comment on this article:

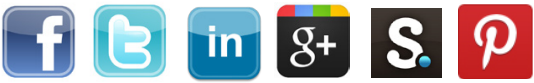

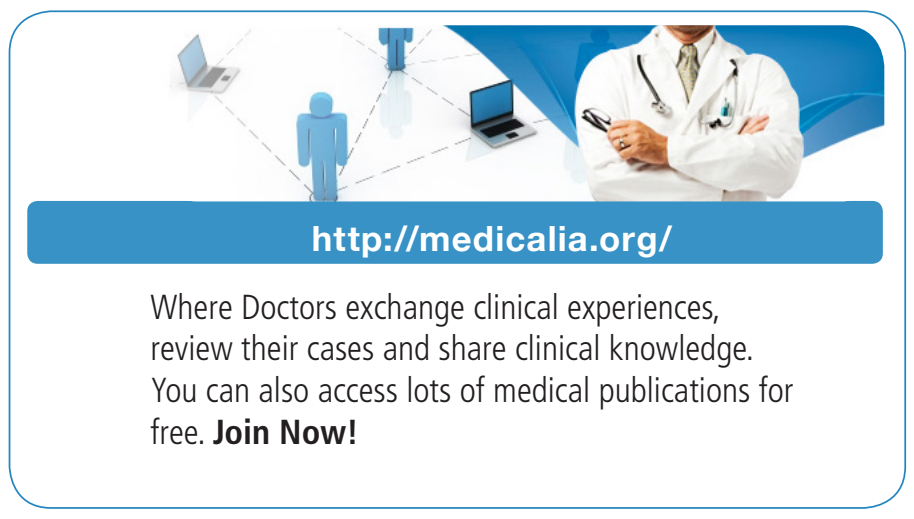

\section{Publish with iMedPub}

\section{http://www.imed.pub}

International Archives of Medicine is an open access journal publishing articles encompassing all aspects of medical science and clinical practice. IAM is considered a megajournal with independent sections on all areas of medicine. IAM is a really international journal with authors and board members from all around the world. The journal is widely indexed and classified Q1 in category Medicine. 